Original Research Paper

\title{
Efficiency Management System as a Tool to Monitor Lecturer's Performance
}

\author{
Yimer Amedie Muhie, Abeselom Befekadu Wolde and Cheru Haile Tesfay \\ Department of Information Technology, Assosa University, Assosa, Ethiopia
}

\author{
Article history \\ Received: 02-09-2020 \\ Revised: 02-11-2020 \\ Accepted: 07-11-2020 \\ Corresponding Author: \\ Yimer Amedie Muhie \\ Department of Information \\ Technology, Assosa University, \\ Assosa, Ethiopia \\ Email: ymr4u.asu@gmail.com
}

\begin{abstract}
Monitoring the actual performance of lecturers is a challenging task in higher education institution, especially in developing countries. Lecturer's academic performance have been appraised using different parameters in Assosa University, Ethiopia. Mandatorily, lecturers are evaluated using printed check list. For the last few years we observed that, the lecturer efficiency score is found on the shelf and not checked by anyone to know the gaps and to establish follow-up system. The use of intranet based web system is better to use lecturer's efficiency result to monitor their performance and to establish follow-up mechanism. In this study, a web based yearbook efficiency management system for evaluating and monitoring the performance of lecturers was designed and developed. The evaluation process in the system were presented according the university evaluation format. The output generated by the proposed system can be used by lecturers, HoD, HRM and academic managers to monitor teaching performance.
\end{abstract}

Keywords: Performance Monitoring, Performance Evaluation, Lecturer's Efficiency, Development of Software

\section{Introduction}

Today, advancement of technologies changes almost all our day to day activities all over the world. This is because of technology is considerably changing the entire way of human life and their activities. Educational system is the most relatively benefited systems from the technologies which gradually changes the techniques of teaching, learning and evaluation process and the key to improving education (Elletsom, 2015; Gálvez Suarez and Milla Toro, 2018). With this, in countries educational system, the educators have a lion role to produce academically top ranked, skillful, innovative and disciplined citizen. In this regard in addition to other factors, higher education institutions' lecturers are the key for the success of students (Wu et al., 2019; Stelnicki et al., 2015; Bain et al., 2011). Without question, the performance of lecturers have greater impact on quality of education, student's academic skillfulness and innovativeness. Therefore, the performance of lecturers' must be continuously evaluated and improved by establishing follow up system (Blair and Valdez Noel, 2014; Lemma et al., 2018).

In Ethiopian higher education institutions, lecturers are evaluated by students, colleagues and Head of Departments (HoD). The evaluation is conducted at the end of each semester and the lecturers have semester efficiency as well as yearly efficiency which is average efficiency of the two semesters.

In this technological era, there must be a way of evaluating lecturers using simple process. In this study, intranet based follow up mechanism is proposed. In this way, the performance of lecturers' using web based system is recorded, evaluated and submitted to the department. Using the proposed system, the lecturer's evaluation result is used not only to get just a score as a measure of efficiency but also to improve performance. Also it saves staff time and energy as well as university resources because the processes of manually preparing, packaging, distributing, collecting, analyzing and reporting results are replaced by the proposed system. In the following sections problem of statement, objectives, methods and materials, results and discussions as well as conclusions are discussed.

\section{Statement of the Problem}

At present, all Universities in Ethiopia uses paper based evaluation system to measure lecturers' efficiency.

The process of this manual system requires high labor, significant timing and resources from preparation to reporting the results. In addition, there is no consistent and constant lecturer's record keeping system in the university. Moreover, it has no significance rather than getting some 
number as a score. This is because, no one is going back to the score to check the efficiency of the lecturer to provide feedback and to establish follow-up system of lecturers. Even the lecturers themselves could not see the individual student's feedback, every score in each measurement parameters, overall strength and weakness, etc. Due to this, the lecturers have no mechanism to know themselves professionally, to improve their work, to upgrade themselves, to increase their readiness. Also the head of the department as well as other concerned bodies have no mechanism to get gaps in the lecturers and to provide continuous professional development in the university to achieve quality of education. This shows that, in the current lecturer evaluation, there is lack of suitable implementation and following up processes. The real purpose of lecturer's in strengthening the teaching profession is declined by the condition of inadequate implementation (Gálvez Suarez and Milla Toro, 2018).

\section{Objectives}

\section{General Objective}

The main objective of this study is to examine the use of yearbook efficiency management system to monitor lecturer's performance.

\section{Specific Objectives}

The specific objectives of this study are:

- To conduct the challenges and potential uses of lecturer's performance evaluation and monitoring

- To identify the specification of intranet based lecturer's performance evaluation system

- To design the system including the backend and frontend

- To develop, test and implement the system

\section{Scope of the Study}

Due to budget and time constraint, the development, testing and implementation of intranet based lecturer's performance evaluation system of this study is conducted only in Assosa University, Ethiopia.

\section{Significance of the Study}

The output of this study is very necessary and important because of the following reasons:

- Every semester's lecturer overall performance will be monitored

- Evaluating, calculating, reporting and accessing lecturer's performance will be easy

- The resources and efforts required to generate report, keeping records and analyzing lecturer performance will be easy

- It will allow all the learners to participate in the evaluation process

\section{Performance Evaluation}

Performance evaluation is the ongoing process used to identify, assess and improve the performance of individual educator in line with the institution's main objectives (Samuel and Berhanu, 2019). Lecturer's performance evaluation is a process in which higher education institutions use to review and rate lecturer's performance and effectiveness. The results are used to indicate lecturer's performance and to provide feedback for area of improvement and support as well as to recognize and reward lecturers (Bichi, 2017). Therefore, improving the evaluation process itself is required for educational success (Flores and Derrington, 2018).

\section{Impacts of Performance Evaluation in Professional Development of Lecturers}

Inappropriate efficiency results of lecturers greatly impacts the learners and educators by influencing both to have fake personality. This is because sometimes the evaluation is conducted for the sake reporting (Samuel and Berhanu, 2019). However, it must be for identifying, measuring and developing an individual's performance.

Real implementation of performance evaluation is the best way of improving professional development of lecturers (Taylor and Tyler, 2012). To achieve quality education through well performed lecturers, technology based evaluation is the top and effective form of lecturer's performance appraisal to reward and recognize the best lecturer. Therefore, the technology based performance evaluation is very important for professional development and quality of education so that area of improvement for lecturers can be easily identified.

\section{Intranet Based Web System (IBWS) for Lecturer's Performance Monitoring}

Appraising performance of lecturers will be interesting and easily accessible if it is supported by web based system. It provides a number of benefits like elimination of printed evaluation forms, keeping of accuracy, confidentiality and integrity of evaluation data, generating timely and accurate report, increasing participation of students in the evaluation process, saving costs and others (Anido, 2009).

The process of evaluating lecturers involves three parties: Students, colleagues and the head of department. The head of department is at the center of managing lecturers' evaluation. In the context of Assosa University, Ethiopia, web based tool is required for its effectiveness, to create easy communication among all parties and to establish follow up mechanism. Therefore, there is need for a system to manage lecturers' evaluation process and to help lecturers to use the evaluation result for performance improvement. In this study, yearbook efficiency management system is proposed and implemented to monitor the performance of lecturers. 


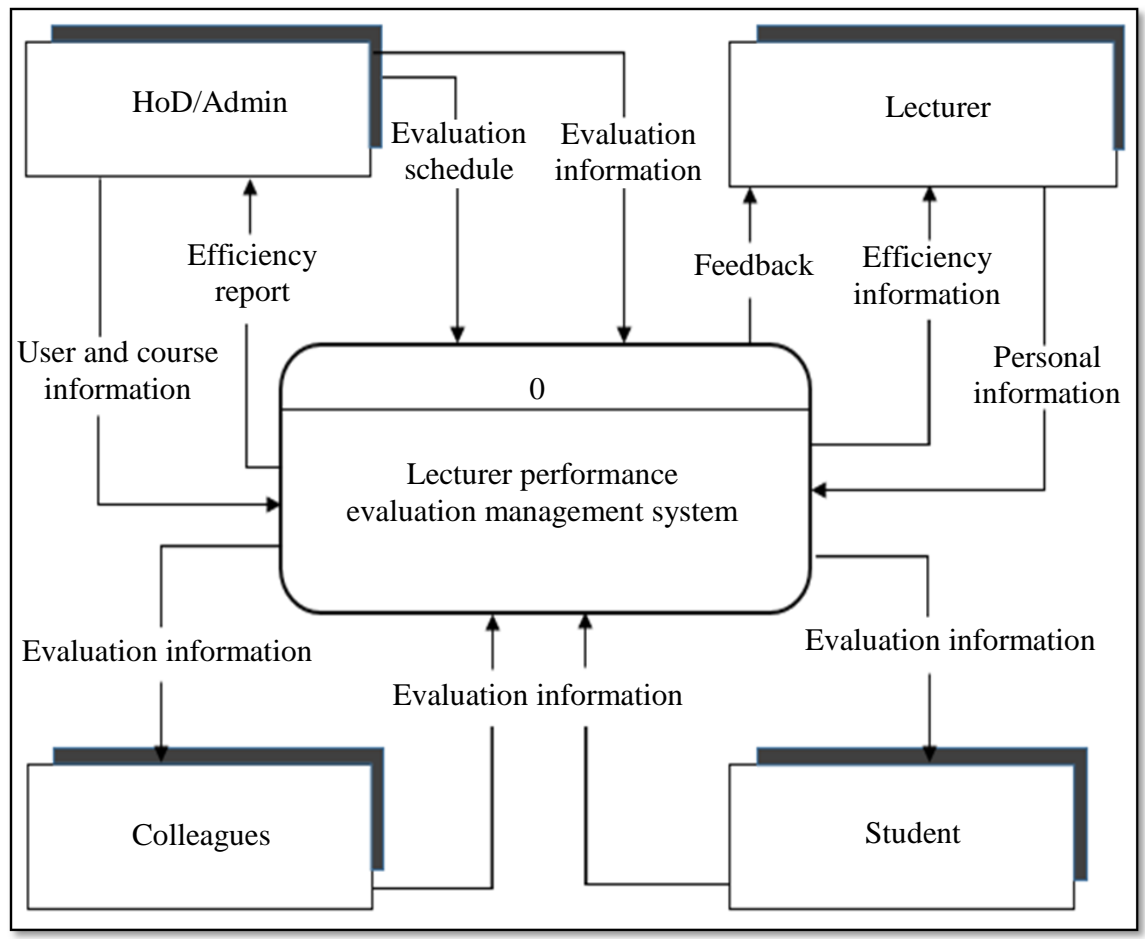

Fig. 1: Context diagram of lecturer performance evaluation management system

\section{Modules in IBWS}

The following seven important modules are examined for the proposed system. Additional modules can easily be integrated into the system so that system functionalities are decomposed according to modules which are recommended approach to handle design and implementation tasks (The Open University, 2018). The modules are:

- User module (HoD, student and colleagues or lecturers in the same department)

- Performance monitoring module

- Scheduling module

- Inter-department communication module

- Comment analysis module

- Searching module

- Administering module

\section{Design of the IBWS}

Designing of a system is the process of defining the system element and it can be expressed using different techniques. In this study context diagram is used to show the design of yearbook efficiency management system. This is because it can easily demonstrate the overall system and its interaction with the external entities which is a level 0 data flow diagram. Figure 1 shows the design of lecturer performance evaluation management system.
Design of Algorithm for Selected Process of Performance Evaluation

Description of Problem: Improving lectures performance evaluation process and result keeping using intranet based web system.

Objective: To develop intranet based lecturer evaluation system to monitor their performance.

Process of performance evaluation 1:

Name: Head of department (HoD)

Input: The HoD enters the URL of lecturer's evaluation system

Output: It displays a page for userID and password

Description: This interface is used by the HoD and is used to display the login page

Logical process:

1. Enter the URL

2. Displays a page for userID and password

3. Enter userID and password

4. If(userID==null $\|$ password==null)

\{

Error in userID and Password

Displays: Please enter correct userID and password

Redirect to login page

\}

Else

\{

Displays HoD interface

\} 


\section{Process of performance evaluation 2:}

Name: lecturer performance evaluation by students

Input: the student click on start evaluation menu

Output: it displays a page for evaluation

Description: start evaluation menu is used to evaluate lecturer for specific course and semester.

\section{Logical process:}

1. Click on start evaluation menu

2. Displays a page for evaluation

3. Select the lecturer name, course code, semester and year

4. If(all fields != null)

\{

Displays lecturer evaluation parameters;

Evaluate lecturer and submit the results; \}

Else

\{

The evaluation page is displayed again with an instruction to enter all fields;
Process of performance evaluation 3:

Name: generating performance evaluation report

Input: the HoD click on report menu

Output: it displays a page for generating efficiency report

Description: this page is used to generate semester and yearly efficiency of individual lecturer.

Logical process:

Click on report menu

Displays a reporting page

Select the lecturer full name, semester and year

If(all fields != null)

\{

Displays lecturer efficiency reporting page;

Generate the report;

\}

Else

\{

The efficiency reporting page is displayed again with an instruction to enter all fields; \}

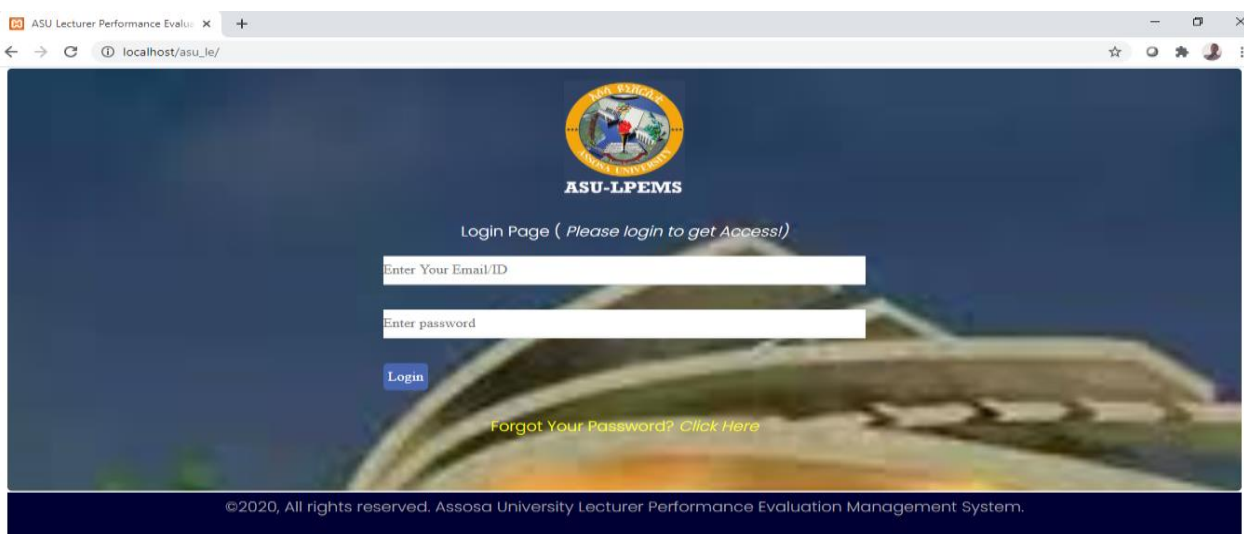

Fig. 2: Login page for lecturer performance evaluation management system

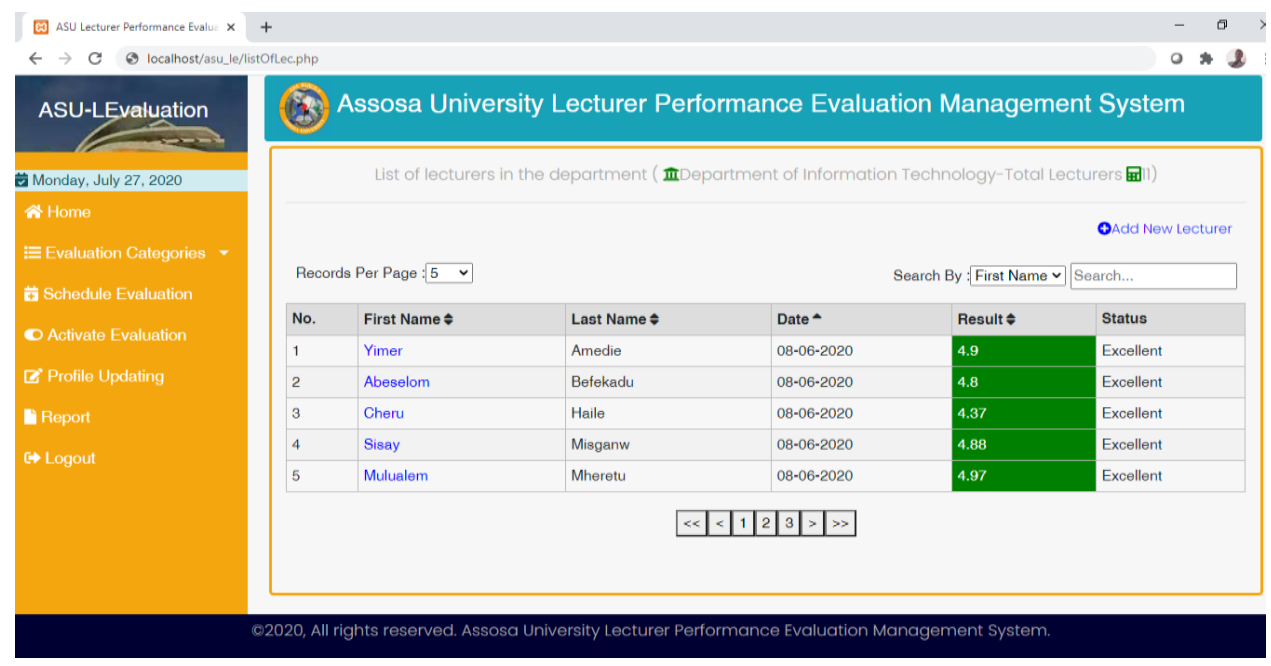

Fig. 3: Lecturer performance evaluation management page for $\mathrm{HoD}$ 


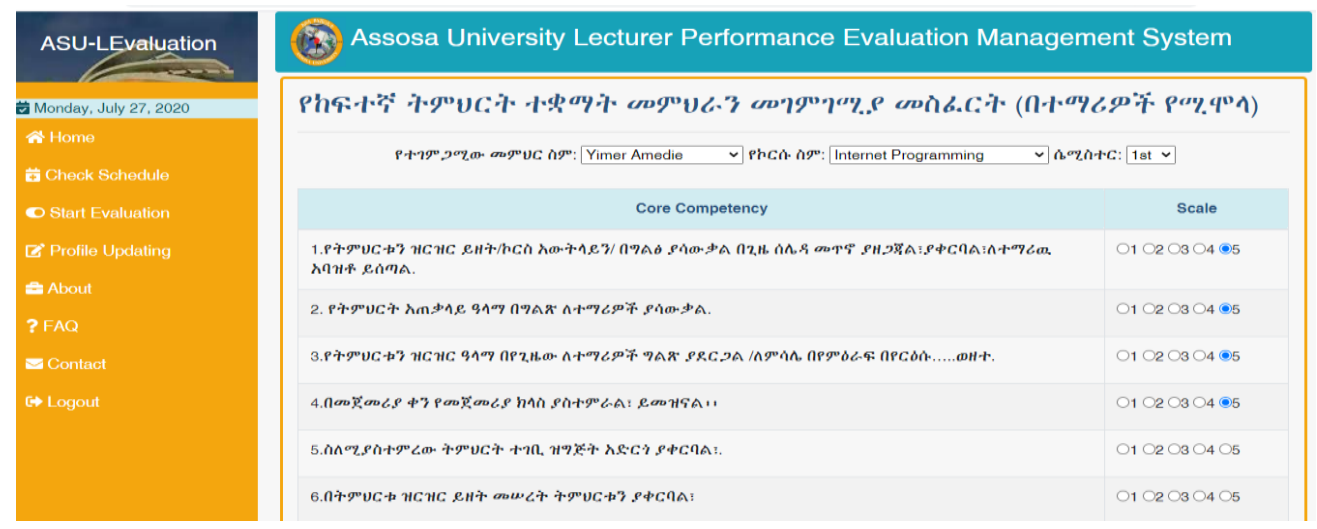

Fig. 4: Lecturer evaluation page for students

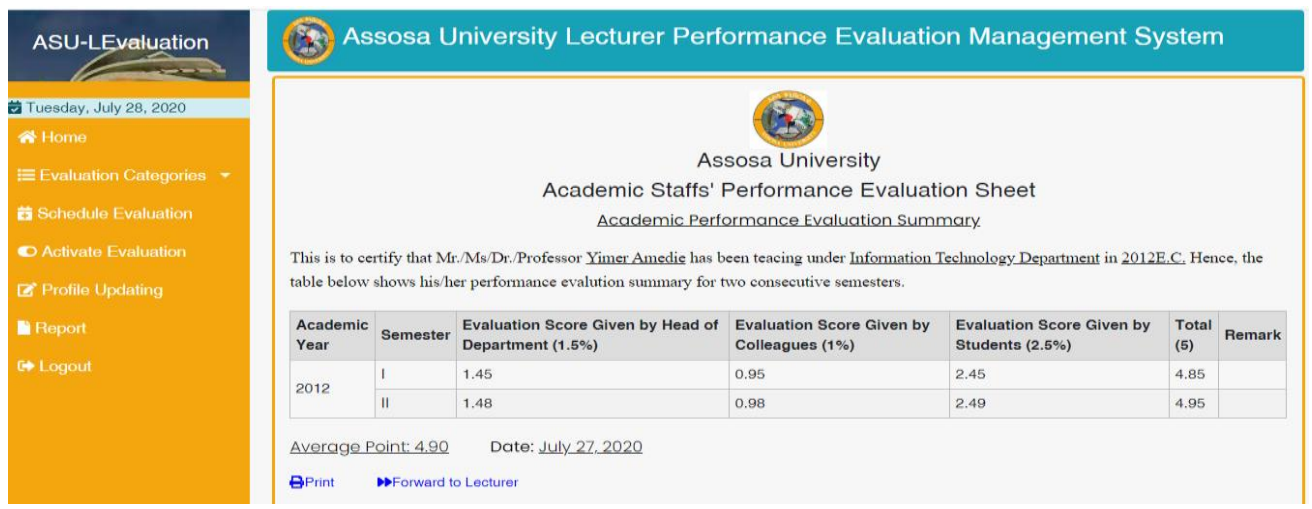

Fig. 5: Semester and yearly efficiency reporting page

\section{Sample Snapshots}

For the purpose of proof of concept, sample snapshots from the developed system are included in this part. Figure 2 shows the login page, Fig. 3 shows Lecturer performance evaluation management page for HoD, Fig. 4 shows lecturer evaluation page for students and Fig. 5 shows Semester and yearly efficiency reporting page.

\section{Evaluation}

The yearbook efficiency management system was evaluated by expertize from the area of computer science, information Technology, education and software engineering at the early stage of the design to check its functionality and usefulness of appraising and monitoring lecturer's performance. To check the workability of the developed solution, system test was performed through unit testing, integration and usability testing. The evaluation was done by taking sample test cases and by observing and checking expected outputs which is discussed below.

\section{Unit Testing}

The proposed lecturer's performance evaluation system has been tested in perspective of appraising lecturer's performance, analyzing and generating efficiency reports. After in has been implemented, each module is tested independently based on the test case in Table 1.

\section{Integration Testing}

This system was integration of different components and tested based on unit module, completeness of module and by creating integrated test condition for all modules as shown in Table 2 . The following integration test conditions were used:

- Efficiency result and comment storing and retrieving test, file processing test and search test were checked. Each module are validated based on providing input and using output

- Integration was done for evaluating lecturer, analyzing and calculating efficiency score, generating efficiency report and monitoring lecturer's performance

\section{Usability Testing}

Usability test was done on the perspectives of head of departments, students and colleagues. This test was 
performed on how all the above users use the system and attractiveness of the interface to use. They used the designed user interface and other features of the developed system. Finally, they suggest different additional issues that are to be included in the system. Therefore, usability testing was done with 45 students, 3 head of departments and 30 colleagues from three different departments in the university. To test the system, each group of the above users uses their own pages that created for them and evaluate the result in terms of usability of the system on the university local internet. Usability testing results are shown in Table 3.

The result analysis of the system uses Likert scale in rating. The ratings are 1(poor), 2(fair), 3(good), 4(very good) and 5(excellent). As the user of system shows, proposed solutions makes work easier which they rated as good, very good and excellent by 25.36, 50 and $25.64 \%$ of the respondents respectively. The user interface of the system is interactive rated as fair, good, very good and excellent by 5, 14, 22 and 59\% of the respondents respectively. The Ease of use in all provided features (register and login, access lecturer evaluation resources, evaluating lecturers, analyzing and generating reports) is rated as fair, good, very good and excellent by $12.5,25,25$ and $37.5 \%$ of the respondents respectively. The users can successfully access and share their resources electronically is fair, good, very good and excellent by $15.5,25,27.5$ and $32 \%$ of the respondents respectively. Implementing intranet based web system to appraise and monitor lecturer's performance for costeffectiveness is rated as fair, good, very good and excellent by $12.5,25,25$ and $37.5 \%$ of the respondents respectively. The time required to evaluate lecturers is rated as fair, good and very good by $25,37.5$ and $37.5 \%$ of the respondents respectively. Using yearbook efficiency management system to monitor lecturer's performance is rated as good, very good and excellent by $12.5,37.5$ and $50 \%$ of the respondents respectively. The system works properly using your mobile phone is rated as good, very good and excellent by 37.5, 25 and $37.5 \%$ of the respondents respectively. The following table shows the usability result set together with the lead questions and number of rating.

Table 1: Unit test cases

\begin{tabular}{llll}
\hline TC ID & TC Objective & TC description & Expected output \\
\hline 1 & $\begin{array}{l}\text { Registering users by identifying } \\
\text { their level } \\
\text { Get access to the evaluation resources }\end{array}$ & $\begin{array}{l}\text { Click on registration from the front } \\
\text { page and provide information } \\
\text { Click on login from the front page and } \\
\text { provide information } \\
\text { Click on start evaluation menu and } \\
\text { click on submit button after finishing } \\
\text { Click on report menu and provide the } \\
\text { information }\end{array}$ & $\begin{array}{l}\text { Store the evaluation data in } \\
\text { to database } \\
\text { Efficiency report analyzed and } \\
\text { retrieved from the database }\end{array}$ \\
\hline
\end{tabular}

Table 2: Integration test cases

\begin{tabular}{llll}
\hline TC ID & TC objective & TC description & Expected output \\
\hline 1 & $\begin{array}{l}\text { Check the link between evaluation } \\
\text { category and activate evaluation }\end{array}$ & $\begin{array}{l}\text { Click on evaluation category link and } \\
\text { then activate evaluation link }\end{array}$ & $\begin{array}{l}\text { To be directed to activate evaluation } \\
\text { from evaluation category }\end{array}$ \\
& $\begin{array}{l}\text { Check the link between check } \\
\text { schedule and start evaluation }\end{array}$ & $\begin{array}{l}\text { Click on check evaluation link and } \\
\text { then start evaluation link }\end{array}$ & $\begin{array}{l}\text { To be directed to start evaluation } \\
\text { from check evaluation }\end{array}$ \\
\hline
\end{tabular}

Table 3: Usability testing result

\begin{tabular}{|c|c|c|c|c|c|c|}
\hline No & Questionnaire & 1 & 2 & 3 & 4 & 5 \\
\hline 1 & Is intranet based lecturer's evaluation solutions make evaluation and reporting easier? & & & 19 & 39 & 20 \\
\hline 2 & Is the user interface of the developed system interactive? & & 4 & 11 & 17 & 46 \\
\hline 3 & Is all the necessary function found in the main menu & & 3 & 7 & 27 & 41 \\
\hline 4 & Is the evaluation module easy to use? & & 2 & 8 & 20 & 48 \\
\hline 5 & Is the developed system easy in evaluating lecturers and giving feedbacks? & & 6 & 7 & 50 & 15 \\
\hline 6 & Is the developed system easier for HoD, colleagues and students to evaluate lecturers? & & 5 & 15 & 19 & 39 \\
\hline 7 & Is the implementation of lecturer's evaluation solution cost effective? & & 7 & 23 & 17 & 31 \\
\hline 8 & Do you think that the time required to evaluate the performance of lecturer's will be improved? & & & 11 & 21 & 46 \\
\hline 9 & Do you think that this system improve the evaluation process? & & & 13 & 22 & 43 \\
\hline 10 & Is the developed system will effectively improve the performance of lecturers? & & & 40 & 20 & 18 \\
\hline 11 & Is overall developed intranet based system impressive? & & 11 & 22 & 45 & \\
\hline
\end{tabular}




\section{Methodology}

To examine the use of yearbook efficiency management system to monitor lecturer's performance, different methods and techniques were employed. Programming and tools techniques, evaluation and testing mechanisms as well as review of literatures were used.

\section{Research Design}

Research design is the main part of any research work and there are a number of approaches based on the nature of the study. Design science research methodology is one of the design approach in the area of computer science and software engineering (Bisandu, 2016; Dresch et al., 2015). It creates an artifact by artificial object and its basic objective is to produce new knowledge during this process. It is mostly focus on knowledge flows and process steps that is problem awareness, suggestion, development, evaluation and conclusion; eventually aims to get result or output (Fallman, 2007).

To show the usefulness of the yearbook efficiency management system for monitoring the performance of lecturers, design-oriented research methodology was used. Design science research method is basically a problem solving model (Hevner et al., 2004). The five steps of design science method followed in this study are identification of problem, suggestion of solutions, application development, evaluation and conclusion.

\section{Identification of Problem}

In this study, the first step ways to identify the problem by examining the current practices of lecturer evaluation and by reviewing the available literatures to acquire understanding and to get its problem domain. Currently, all Universities in Ethiopia uses paper based lecturer's evaluation technique in which the filled data can be lost at any time and only $15-25 \%$ of learners are participated in the evaluation process. Moreover, the process is resource, time and effort intensive to prepare, pack, distribute, collect, record, analyze, store and report the result.

\section{Suggestion of Solution}

The second step was to identify various solutions that can solve the problems of lecturer's performance evaluation and monitoring process. In this regard, intranet based web system is proposed as a solution to monitor lecturer's performance.

\section{Development of Solution}

The third step was the development of the selected solution. Here, yearbook efficiency management system was designed and implemented which is intranet based web system to evaluate and monitor lecturer's performance.

\section{Evaluation}

Evaluating the designed and implemented solution was the fourth step in this study. The developed yearbook efficiency management system was evaluated using the different stages of software development testing techniques. So, unit testing, integration testing and usability testing was done accordingly.

\section{Conclusion}

The final step of this study was to put concluding remarks based on the results and discussion of the study and the evaluation of the proposed solution for the specified problem.

\section{Tools}

In order to accomplish this study software, programming and hardware tools were used.

Software Tools:

- Web browser

- Text editor

- E-Draw Max to draw diagrams

- Adobe Photoshop to create and edit logo and other necessary photos

- MySQL to store all the evaluation data or as a database system

- Apache webserver

- phpMyAdmin as PHP and MySQL administration tool

- Xampp

Programming Tools:

- HTML5, CSS and bootstrap open source framework for designing the web interface

- JavaScript and JQuery to write client side logic like validation and form submit

- PHP language to write backend side or server side business logic

Hardware Tool:

\section{- Computer}

\section{Results and Discussion}

The current practice of appraising lecturer's performance is through paper based method where the evaluation questionnaires are prepared, printed, packed, distributed, collected, recorded, analyzed and reported manually by the head of departments and other facilitators.

The paper based evaluation process had many problems during its implementation (Anido, 2009). The first problem is related with the required time to record, 
analyze and generate report which takes a long time. The second problem is regarding to the number of students participated to evaluate their lecturers. In this regard, because of the manual evaluation process is resource and time intensive to prepare, record and analyze the result, only $15-25 \%$ of the students were participated in the evaluation process. So, all the students had no chance to evaluate their lecturers. The third challenges of paper based evaluation is connected with inappropriate result given to lecturers. This is because of the lecturer is being there during evaluation time and the students fear of facing challenges by connecting the issue with grade mark, they may gave high score even if he/she deserves the lowest score. The forth problem is the cost of printing and recording points for each evaluation parameter. The fifth problem is regarding to the limitation to share the efficiency results of lecturers when needed. Because the result is printed and putted on the shelf, academic managers can't access the information when they need. The last but not the list challenges of paper based evaluation process is related with confidentiality, data accuracy and integrity which is under question. Because of more than one person is participated in the conduct and data encoding process, it may not be confidential. Also, error may happen intentionally or unintentionally when evaluation score is entered in to computer for processing.

As a solution of solving the above discussed and other related issues of the evaluation, intranet based lecturer's evaluation system was designed and implemented in Assosa University, Ethiopia. So, the use of intranet based lecturer's evaluation system in current context is due to the problems faced by universities to appraise and monitor the actual lecturer's performance to establish follow up system and professional development program. As known, technologies have a potential to achieve radical change in many sectors including education and training (Anido, 2009; McKenney and Visscher, 2019). This is because, technology based lecturer performance evaluation have a lot of potential uses from preparation of evaluation to result reporting and improvement of lecturer's profession to achieve quality of education (Gálvez Suarez and Milla Toro, 2018). Compared with the manual way of lecturer evaluation, it is effective in evaluating and monitoring, accessible when needed, it saves cost and eliminates printing of papers, allows participation of all students in the evaluation process with the absence of any lecturer or facilitators during the evaluation, confidentiality, integrity and accuracy can be easily maintained, timely and accurate report which allows retrieval of specific and detail information from digital media. Therefore, there will be monitoring of lecturer's teaching performance with in-depth analysis of lecturer performance report to provide feedback and recommendation, to assign the right teaching load, to prepare training and professional development by allocating budget as well as to recognize and reward the best performer. However, there is security issue which requires specific and serious protocol that must be enforced during the evaluation period.

\section{Conclusion}

In higher education institutions of Ethiopia, lecturer's efficiency result have not been produced noticeable contribution for the improvement of lecturer's performance and to establish professional development method. This is because of the lack of technologies to evaluate the performance of lecturers, to establish monitoring mechanism and to find professional gaps. In this study, we proposed web based lecturer's yearbook efficiency management system as a tool of performance improvement for lecturers. Different modules of the system have successfully been developed and integrated into the final version. The developed intranet based web system is used to monitor lecturer's performance and to establish professional development and follow up system.

In the future, we planned to automatically analyze the comments given by students, colleagues and HoD to generate report. This is by integrating the concept of NLP and AI to categorize and summarize comments as strength and weakness. Also we planned to integrate the yearbook efficiency management system with the university registrar, academic program development and human resource management system to cluster lecturer information for later use.

\section{Acknowledgement}

We gratefully thanks the first reviewers of this study for their contractive comments and suggestions. Also we thanks all who support us in different ways and their appreciation.

\section{Author's Contributions}

Yimer Amedie Muhie: Proposing the idea, collecting and analyzing necessary resources, developing the system and writing the manuscript.

Abeselom Befekadu Wolde: Collecting part of the resources, editing and reviewing the manuscript.

Cheru Haile Tesfay: Collecting part of the resources, editing and reviewing the manuscript.

\section{Ethics}

There are no ethical issues in this study so that all the authors read and approved the final manuscript before submission. 


\section{References}

Anido, C. I. (2009). Online Teaching Performance Evaluation System: A Tool for Quality Education. In Proceedings EISTA '09-7th International Conference on Education and Information Systems, Technologies and Applications.

Bain, S., Fedynich, L., \& Knight, M. (2011). The successful graduate student: A review of the factors for success. Journal of Academic and Business Ethics, 3, 1 .

Bichi, A. A. (2017). Evaluation of Teacher Performance in Schools: Implication for Sustainable Development Goals. Northwest J. Educ. Stud, 2(1).

Bisandu, D. B. (2016). Design science research methodology in Computer Science and Information Systems. International Journal of Information Technology, 5(4), 55-60.

Blair, E., \& Valdez Noel, K. (2014). Improving higher education practice through student evaluation systems: is the student voice being heard?. Assessment \& Evaluation in Higher Education, 39(7), 879-894.

Dresch, A., Lacerda, D. P., \& Antunes, J. A. V. (2015). Design science research. In Design science research (pp. 67-102). Springer, Cham.

Elletsom, H. A. (2015). The eLearning Africa Report. Elearning Africa. www.elearningafrica.com/report

Fallman, D. (2007). Why research-oriented design isn't design-oriented research: On the tensions between design and research in an implicit design discipline. Knowledge, Technology \& Policy, 20(3), 193-200.

Flores, M. A., \& Derrington, M. L. (2018). Improving teacher evaluation: key issues for appraisers in a globalised era.
Gálvez Suarez, E., \& Milla Toro, R. (2018). Teaching Performance Evaluation Model: Preparation for Student Learning within the Framework for Teacher Good Performance. Journal of Educational Psychology-Propositos y Representaciones, 6(2), 431-452.

Hevner, A. R., March, S. T., Park, J., \& Ram, S. (2004). Design science in information systems research. MIS quarterly, 75-105.

Lemma, G., Leka, W., \& Tebeje, W. (2018). Evaluation of the Effectiveness of Teaching and Learning in Public Higher Education Institutions of Ethiopia. The Ethiopian Journal of Higher Education, 5(1), 127-176.

McKenney, S., \& Visscher, A. J. (2019). Technology for teacher learning and performance.

Samuel, C., \& Berhanu, E. (2019). Practices and Challenges of Appraising Teacher's Performance Appraisal in Government Preparatory Schools of Wolaita Zone, South Ethiopia.

Stelnicki, A. M., Nordstokke, D. W., \& Saklofske, D. H. (2015). who is the successful university student? An analysis of personal resources. Canadian Journal of Higher Education, 45(2), 214-228.

Taylor, E. S., \& Tyler, J. H. (2012). The effect of evaluation on teacher performance. American Economic Review, 102(7), 3628-51.

The Open University. (2018). Approaches to software development. http://www.open.ac.uk/courses/modules/tm354.

Wu, C. C., Yang, C. Y., Hwang, M. S., \& Lin, M. Y. (2019). The design and application of a web-based teacher evaluation system for STEM education. The International Journal of Electrical Engineering \& Education, 0020720919852783. 